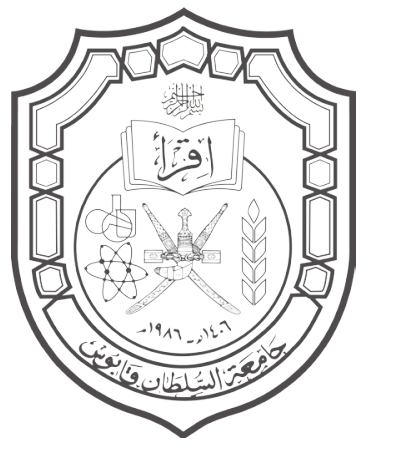

The Archaeological Records of Oman: The Challenge of Information Management

Mohammed Ali K. Al-Belushi 


\title{
The Archaeological Records of Oman: The Challenge of Information Management
}

\begin{abstract}
Although Oman's National Heritage Protection Law (NHPL) of 1980 explicitly emphasises the importance of recording the country's archaeological resource, no major attempt has yet been made to quantify it in a truly comprehensive way. And what few attempts have been made to do so in consistent and standard ways have seen attention limited to specific geographical regions and usually with research objectives that did not include recording.

With Oman's accelerating pace of modernization since the 1970s, parts of the nation's archaeological resource have become exposed to and endangered by both natural and human factors. Some components have been partially destroyed, others increasingly threatened. It is, therefore, beyond dispute that the establishment of a national archaeology record is an urgent need. In response to such a reality, this paper highlights the neglected role of the archaeological records in the practices of both researchers and management. It reviews the present practices of the relevant bodies when compiling, verifying, storing, managing and exploiting information related to the nation's archaeological resources. The paper also examines existing records in terms of their aims, scope, development, usage, limitations and adequacy. Finally, it suggests ways to enhance current practice and establish a national record of archaeological resources.
\end{abstract}

\section{Keywords:}

Oman, archaeological databases, archaeological records, archaeological resource management.

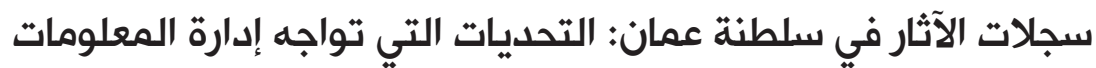

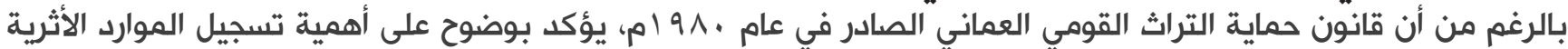

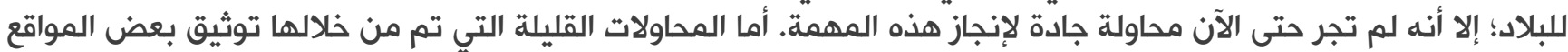

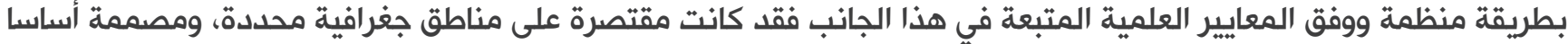
لتحقيق أهداف بحثية بحتة ليس التوثيق جزء السير أساسيا منها.

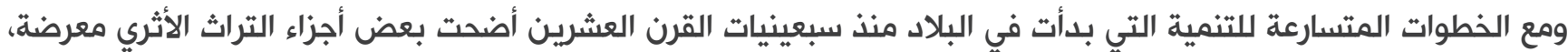

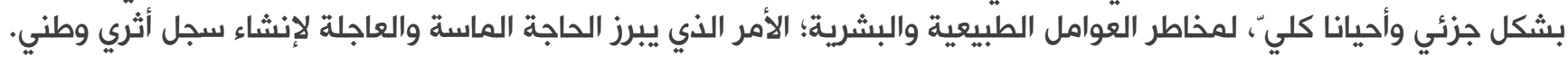

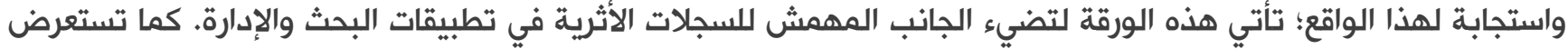

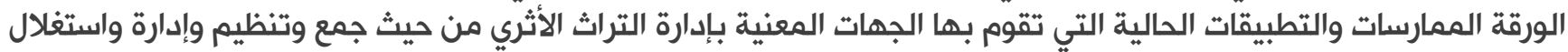

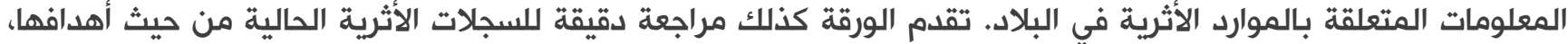

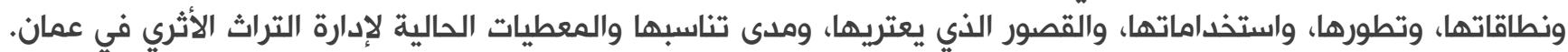

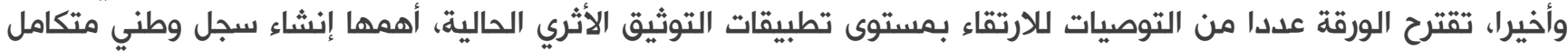
للموارد الأثرية في عمان.

كلمات مفتاحية: عمان، قواعد البيانات الأثرية، السجلات الأثرية، إدارة الموارد الأثرية 


\section{INTRODUCTION}

A glance at the methodologies adopted within the field of archaeology at the beginning of the new millennium is sufficient to understand the extent to which perspectives and scope have widened. One manifestation of this is the shift from traditional ways of managing archaeological data. Introducing information technology, with its great capacity for storing and handling information, has spread a 'high-spirited optimism' throughout most parts of the discipline (Madsen, 2001: 101) and has played a considerable role in reformulating old management ideas (Wheatley 1995, p. 171).

Throughout the world, as archaeological resources have been increasingly exposed to the destructive agents of modernisation and weathering, scholars in the discipline have found themselves forced to extract and record the 'maximum possible information from what still survives' (Greene 1983, p.130) by employing all available methods, among which information technology is, undoubtedly, the most promising. As a result of using this technology, new types of data have been generated and answers to old questions found for the first time. This in turn has led to the accumulation of huge quantities of complex information, management of which, without using computers and quantitative thinking, would be almost impossible (Barcelo et al 1999, p. 2).

Nowadays, as the quantity and complexity of data are growing rapidly, most archaeologists engaged in consolidating and advancing the relatively new field of resource management are aware of the necessity, the potential advantages and fundamental role that information technology can play in handling this data. Advances in information management programmes and data examination techniques made possible by high-speed computers allow archaeologists to be 'in a position to record different kinds of data, and to explore that data more fully than ever before' (Reilly and Rahtz 1992). This is in addition to the possibilities of integrating greater quantities of information from different sources and comparing it within the applications of geographical information systems (GIS).

But computing and quantitative methods have not always been used adequately and effectively. It has long been noticed that statistical methods, for instance, have been misused (Thomas 1978, p. 233) and many databases have been designed without enough attention to such important concerns as standardisation, retrievability and other technical problems. It is now understood that adopting 'certain structuring and homogeneity' (Arroyo-Bishop and Zarzosa 1992, p. 133) in data compiled and produced is essential if archaeological research and/or conservation are to be effective.

The use of highly structured databases, a truly major advance in the field of archaeological resource management, serves an essential purpose in easing the processes of recording, controlling, synthesizing and exploring the different types of data related to the resource (Niccolucci et al 2001, p. 108). And the new demands made on archaeology by modern societies have led many countries to devote considerable amounts of money and effort to computerizing their manual records (Larsen 1992, p. 3).

Decisions and estimates are made daily within bodies dealing with archaeological resource management, and the availability of databases with such related quantitative techniques as statistical analysis provides investigators and decision makers with 'intelligent means for wrenching an understandable simplicity from an unmanageable complexity' (Thomas 1978, p. 233). It also allows them to make appropriate decisions. Procedures for decision-making, such as recommendations on a developmental project with significance for components of the archaeological resource, must be fast and 
uncomplicated. But this is impossible without a complete record linked to other kinds of information, particularly that related to the natural environment. The absence of such a record not only delays the issuing of appropriate decisions but also hinders the possibility of producing a comprehensive picture of the negative impacts and destruction that machine usage may cause.

Daily advances in the field of information technology will, no doubt, impose significant changes on the aims, philosophy and methods of current archaeological record keeping. They will direct professionals to upgrade and enhance their databases by adopting and acquiring ideas and tools from new records. However, this will mean new demands not only from researchers and managers but from the public as well. Although praised for their many advantages, the value of database records lies in how easily audiences can gain access to view and examine their information. Also, the use of different types of interfaces and queries allows audiences to test investigators' interpretations and to combine data from disparate sources in order to 'permit more broadly based retrieval and analysis' (Schloen 1999, p. 301). But satisfying all these demands is not easy. It needs great effort and support from archaeologists, record creators, curators and the public.

Not surprisingly, the last two decades have witnessed a quantum leap in the number and type of archaeological records. With the aid of computing, recording a country's resource has become the foundation for almost all aspects of researching and managing this inheritance locally and nationally. Hence the large amounts of money and effort invested in recent years in the creation and development of archaeological records in most modern or 'developed' countries (Larsen 1992, p. 3). However, the application of information technology is not always commensurate with this investment and is still embryonic in many management systems, especially in developing countries.

In Oman, government awareness of the need to record the archaeological resource produced the 1980 National Heritage Protection Law (NHPL) that required relevant bodies to establish and regularly update an inventory of all properties of the national heritage (see below). Since then the Ministry of Heritage and Culture (MHC), the responsible government body, has worked hard to meet this requirement. Its Department of Excavation and Archaeological Studies has devoted available financial and human resources to collating information on the nation's resource for management and research purposes. However, these efforts have not been performed with clear and well-defined plans ${ }^{1}$. Apart from two current databases (see below), which the MHC started building in 1998 from published and unpublished literature arising from specific area surveys, there has, as yet, been no planned and cohesive attempt to record the nation's archaeological resource in a comprehensive way. Hence, to date, no complete and consistent record exists that can reliably be used for research, management, education and other purposes. Thus, in order to obtain specific resource information, researchers must browse through a mixture of unclassified sources produced at different times and with different research objectives. Moreover, while no single work exists which explains the absence of archaeological records in Oman, this lacuna has negatively affected resource management work, and will continue to do so if the relevant bodies take no steps to record the resource using new systematic standards. But before attempting to review the current situation, it might be useful to examine existing legal and administrative

\footnotetext{
${ }^{1}$ It must be noted that Oman is not alone in its defective state of archaeological heritage management as most Arab and African countries suffer from even more serious problems in protecting their cultural heritage in an acceptable manner.
} 
frameworks.

\section{LEGAL AND ADMINISTRATIVE FRAMEWORKS}

The $\mathrm{MHC}$ is the only national body charged with the compilation and maintenance of Oman's archaeological record. However, its current organisational structure does not include a department assigned exclusively to perform such work. Instead, the Department of Excavation and Archaeological Studies (previously known as the Department of Antiquities) and the Departments of Forts and Castles, Projects and Maintenance, and museums are required by the ministry to do this on an ad hoc basis.

The MHC's recording functions and responsibilities were spelt out in the National Heritage Protection Law (NHPL), 1980 (Royal Decree, 6/1980) ${ }^{2}$, the first and only archaeological measure to be passed by the Omani government. It is also the only law whose provisions include regulations for recording the nation's archaeological resource (Articles III, V, VIII, XXXII, and XXXXIII of the NHPL). Article III calls for 'a nation-wide overall inventory to be conducted and regularly updated. It must encompass all properties that form the entire entity of the national heritage. However, a special Royal Decree will be issued for both specifying the methods and procedures to be followed in performing these inventorial tasks and naming the authorities incharge of the same' (P.7). The first part of this article clearly highlights government awareness of the urgent need to establish a nationwide inventory for all components of the national heritage, of which the archaeological resource constitutes a part. Despite this, however, no strategic action plans, even for heritage quantification, have been drafted to meet this need. Indeed, existing archaeological databases are no more than attempts initiated by foreign researchers, though with the ministry's administrative and financial support. The second part of this article declares that the procedures for compiling the inventories will be issued in a later royal decree, but as yet this has not appeared.

Recording issues are also pinpointed by the NHPL in its section devoted to regulations protecting 'Registered Monuments' (specifically; Articles V and VIII). Article V states that the Minister of National Heritage and Culture 'may - whether at his own discretion or at the instance of the landlord or in response to a request raised by the appointed supervisor - decide that a certain monument is of special historical, artistic or scientific importance and must accordingly be duly registered' $(P, 8)$. Furthermore, Article VIII states that 'the Ministry is to prepare and regularly update an authoritative list including all registered monuments and containing a brief description of the respective monuments outlining location, protected surrounding area as well as the names and addresses of landlords or the appointed supervisors as the case may be and date of registration' (P. 9). Despite this requirement for the ministry to list and record monuments of national significance, no official list has yet been produced. Nor is the term 'registered monument' either conceptually or practically used by the ministry (i.e. apart from its presence in the NHPL, there is no such entity as a 'registered monument' in the current resource management system). The NHPL defines a 'monument' as 'each and every ancient structure, building, hill, cemetery, cave, rock, statue, engraving, stone block that may have historical, archaeological, artistic or scientific value/magnitude and dates back to more than sixty years or is considered as a monument according to a Ministerial Decision. The term "Monument" also implies the monument site or any part thereof. It is imperative to demarcate the monument by a pegged perimeter fence, protect its overall appearance and artistic mien

2 It should be noted here that the NHPL was originally issued in Arabic. The researcher has used an unofficial translated version provided by the Department of Excavation and Archaeological Studies of the Ministry of Heritage and Culture. The reader might notice some inconsistency in the use of the terminology found in this version. 
and safeguard it against any potential damage' (Article II: C) (P. 5).

Currently, instead of constructing and maintaining a list of registered monuments, the ministry collects information on the various monument types (without distinguishing between those registered or un-registered) that are noted after, for example, surveying, excavation and restoration. This mostly appears in hard copy form and is stored in separate folders within relevant departments. Information about some monuments may be found, on occasion, scattered across several departments.

TheNHPLincludestheregistration of archaeological portable property within the section devoted to the 'registration of portable cultural property', which states that 'The Ministry is to prepare and regularly update an authoritative list including a detailed description of each and every registered portable cultural property together with pinpointing their respective locations as well as the names and addresses of landlords or the appointed supervisors'. (Article XXXII) (P. 16). Again, as with the term 'registered monument', within the practice of the $\mathrm{MHC}$ there is no distinction between registered and un-registered properties.

Apart from the electronic database (see below) established by the Department of Excavation and Archaeological Studies to maintain a record of (only) the artefacts in its custody ${ }^{3}$, there is still no complete and consistent database for Omani archaeological portable property. Similarly, there are no official databases for artefacts in the possession of museums; instead, each museum has a simple list of its exhibits (mostly comprising paper-based forms). And these lists are produced for archiving purposes and not as databases that can be used for information retrieval.

A distinction is drawn in the NHPL between a 'monument' (described above) and 'structural blocks', which are defined as 'any built structures, whetherconnectedtogetherordismembered, that have historic, artistic or scientific value in terms of architectural design, structural harmony, location/ landscaping vantage or picturesqueness'. (Article II: E) (P. 7). The management and recording of most types of building groups fall mainly under the duties of the Department of Forts and Castles. However, some kinds of historical buildings, such as mosques, are managed by the Department of Excavation and Archaeological Studies. With regard to the issue of recording structural blocks, the NHPL requires the ministry to 'prepare and regularly update an authoritative list including all registered building blocks containing a brief description of the respective blocks and outlining their locations, protected surrounding area as well as the names and addresses of landlords or the appointed supervisors as the case may be and date of registration'. (Article XXXXIII) (P. 20).

Again there is no official record for Omani building groups, apart from the simple lists kept by the departments concerned and the written reports arising from research and management activity undertaken on this resource component.

\section{EXISTING RECORDS: HISTORY AND DEVELOPMENT}

Before attempting to review Oman's existing archaeological databases, two facts should be mentioned. First, there is no official record currently being used for the purposes of research, planning and management. Second, no previous work of any kind has been done to study, evaluate or review archaeological recording. Hence this section investigates existing databases and reviews their aims, scope, usage, current effectiveness and reliability. In addition it describes their structures and methods of construction and attempts to consider administrative and technical aspects relating to their current and future situation.

\footnotetext{
${ }^{3}$ The Department of Excavation and Archaeological Studies' artefacts constitute the output of the excavations and surveys that have been carried out over the years in the Sultanate.
} 
Currently the MHC has two archaeological databases. The first, called the 'Omani Archaeological Sites Information System' (OASIS for short), was designed to record Oman's archaeological sites. The second, called the 'Department of Antiquity Numbers Project' (DAN for short), was designed to record and manage objects stored at the Department of Excavation and Archaeological Studies. The importance of these two databases is that they represent the government's earliest steps towards recording the nationalresourceelectronicallyand systematically. The major effort spent in designing, constructing and populating them is manifest. However, little information is available about them, due to the absence of manuals or guidelines. Hence information on the issues discussed below was collected via personal communication ${ }^{4}$ with those who constructed the databases and by examining the databases themselves.

Both databases came into existence as a result of cooperation between the Ministry of National Heritage and Culture and the French Embassy in Muscat. They were designed, constructed and populated between 1998 and 2001 by three French archaeologists: Frederic Gerard (1998-1999), Kelig-Yann Cotto (1999-2000), and Martin Menu (2000-2001). Financial support was provided by both bodies.

\subsection{OASIS}

OASIS aims to record the nation's archaeological sites and monuments in a retrievable format so that the $\mathrm{MHC}$ can update it and use it for planning and management. It covers the Palaeolithic and late Islamic periods and is principally concerned with all types of archaeological sites, but excluding object types. OASIS was built on data compiled from a literature search only and no field work of any kind was undertaken to populate it. Until December 2007 the number of archaeological

\begin{tabular}{|c|c|c|}
\hline Field Name & Data Type & Description \\
\hline ID & AutoNumber & \\
\hline Name & Text & \\
\hline Encoding & Text & \\
\hline Regional Area & Text & \\
\hline Wilayat & Text & \\
\hline Gazeteer Ref & Number & \\
\hline Map & Text & \\
\hline UTM Northing & Number & \\
\hline UTM Easting & Number & \\
\hline Type of Structure & Text & \\
\hline Structure 1 & Text & \\
\hline Structure 2 & Text & \\
\hline Structure 3 & Text & \\
\hline Structure 4 & Text & \\
\hline Structure 5 & Text & \\
\hline Chronology & Text & \\
\hline Expedition & Text & \\
\hline First Visit & Text & \\
\hline Recorder & Text & \\
\hline Dig Manager & Text & \\
\hline Excavation & Text & \\
\hline Material & Text & \\
\hline Author \& Date & Text & \\
\hline Conservation & Text & \\
\hline Comments & Memo & \\
\hline References & Text & \\
\hline Pictures & Text & $\begin{array}{l}\text { Number } \\
\text { of pictures } \\
\text { available }\end{array}$ \\
\hline Drafts Maps & Text & $\begin{array}{l}\text { Number } \\
\text { of maps } \\
\text { made during } \\
\text { fieldwork }\end{array}$ \\
\hline Registered & Text & $\begin{array}{l}\text { Name of the } \\
\text { recorder }\end{array}$ \\
\hline Updated & Date/Time & $\begin{array}{l}\text { Date of the } \\
\text { record }\end{array}$ \\
\hline
\end{tabular}

Table 1 The physical structure of the OASIS database exactly as it appears in its 'Design View'.

\footnotetext{
${ }^{4}$ Most of the information was provided by Kelig-Yann Cotto and Martin Menu through personal communication throughout the period February to May 2003.
} 
sites it recorded was 1407 (Biubwa Al-Sabri, personal comm., 2007). Structurally, it consists of only one table containing a mixture of basic information about site types, location, chronology, conservation and information sources etc (see Table 1). It does not contain any metadata or guidelines and almost all of the 'Description' fields in its 'design view' are empty.

Among the technical problems and obstacles faced by the team during the construction and compilation of OASIS was the difficulty of locating sites. Coordinates were often unavailable, especially for those sites discovered in the early years of the 1970s (Kelig-Yann, personal comm., 2003).

\subsection{DAN}

DAN was constructed to record archaeological objects stored at the Department of Excavation and Archaeological Studies which had been accumulating since the early 1970s as a result of archaeological activity. These objects lacked any form of retrievable cataloguing prior to DAN's construction and their management had become very difficult in the absence of an electronic register. DAN's data was compiled from the following sources:

- linformation attached to the objects by their original collectors or by staff in the Department of Excavation and Archaeological Studies

- Description and measurement of the physical attributes of the objects

- Additional information from the literature wherever possible

The objects recorded date from most of Oman's archaeological and historical periods. Until December 2007, the number of these objects was 22511 (Biubwa Al-Sabri, personal comm., 2007). But, due to its limited scope and simple structure, DAN cannot be considered a complete record, but rather as an archive registering and cataloguing only objects stored at the Department of Excavation and Archaeological

\begin{tabular}{|l|l|l|}
\hline \multicolumn{1}{|c|}{ Field Name } & Data Type & \multicolumn{1}{c|}{ Description } \\
\hline DA_Number & Text & \\
\hline Slide no & Text & \\
\hline Site 1 & Text & Site name \\
\hline Found & Date/Time & \\
\hline Object & Text & \\
\hline Box & Text & Box number \\
\hline Recorded & Date/Time & \\
\hline By & Text & Name of the \\
\hline Exist & recorder \\
\hline Exhibitions & Text & Where is the \\
\hline Storage 1 & Text & \\
\hline Site & Text & Where is the \\
\hline Site List & Text & \\
\hline Structure & Text & \\
\hline Site Phase & Text & \\
\hline Arabic & OLE Object & \\
\hline Stratigraphy & Text & \\
\hline Expedition & Text & \\
\hline Chronology & Text & \\
\hline Material & Text & \\
\hline OBJECT_FIE & Text & \\
\hline Conditions & Text & \\
\hline Weight & Number & \\
\hline Thickness & Text & \\
\hline Length & Text & \\
\hline Width & Text & \\
\hline Diam 1 & Text & \\
\hline Diam 2 & Text & \\
\hline Des 1 & Yemo & \\
\hline Pictures & Text & \\
\hline Drawings & Text & \\
\hline Photo & YlE Object & \\
\hline Restored & Yeso & \\
\hline Studied & Yexhibited & \\
\hline
\end{tabular}

Table 2 The physical structure of the DAN database exactly as it appears in its 'Design View'

Studies. The structure of DAN is similar to that of OASIS in that it consists of one table containing 
all information regarding the stored objects (see Table 2). Its 'design view' does not include enough description of its data fields.

\subsection{Computerisation of OASIS and DAN}

The hardware used to construct both OASIS and DAN was a Pentium II personal computer of 450 MHz and 64 MB RAM (Kelig-Yann, personal comm., 2003). Both databases were programmed using MS Access2000 software.

\subsection{Updating OASIS and DAN}

The Departmentof Excavation and Archaeological Studies is continuously updating OASIS by adding newly-discovered sites. However, there is only one member of staff doing this as part of his responsibilities for a different job. Similarly, another member of staff is responsible for updating DAN by recording any new object which is to be added to the store of the department.

\subsection{Accessibility to OASIS and DAN}

To date, accessibility to both DAN and OASIS has been limited to staff of the Department of Excavation and Archaeological Studies (i.e. there is no direct and unsupervised access). Although the department does not yet have the facilities to allow its two databases to be directly consulted by external enquirers, it does, from time to time, supply official and private users with information they require.

\subsection{Technical limitations of OASIS and DAN}

Despite the considerable potential benefits to be gained from them, OASIS and DAN currently play a very limited role in plans and practices around the conservation and management of Oman's archaeological resource. In addition to the problems mentioned above, associated with legal and administrative frameworks, there are a number of technical reasons for this limited role associated with the availability of data standards and the extent of database flexibility.

\section{- Availability of data standards}

Both databases lack data standards. They do not provide their users with information (e.g. recording guidelines and terminology standards) about their structure, content and underlying methodology. This has resulted in the limited consistency of their contents which, in turn, has created difficulty in retrieving or exchanging information.

\section{- Structural flexibility of the two databases}

The two databases do notfully utilise the computing and data management facilities offered by MS Access 2000. Among the facilities not used, and in particular by OASIS, is the possibility of recording the different components associated with every site in a hierarchical way. Hierarchically-designed databases allow compilers to record flexibly details of large, complex sites, so that both distinctions and relations between site components remain clearly defined.

\section{THE CHALLENGES}

There are a number of challenges facing Oman's archaeological records that need to be addressed. They are related to the meagreness of the laws, organization, finance, and human resources. Below is a brief discussion of them:

\section{- Inherent limitations of the NHPL}

The lack of an integrated protection policy for managing the Country's archaeological resource, and the lack of practical application of the law's requirements about recording, can be referred to the limitations inherent in the law itself and to administrative difficulties that hamper implementation of legal statutes. A prime reason for the absence of a comprehensive and complete national archaeological record is that the relevant Royal Decree, referred to in the second part of Article III of the NHPL, and intended to define and specify the means by which the archaeological resource should be recorded (also to assign the authorities who should take this responsibility within the ministry), has not yet been issued. Thus, the concept and requirements drawn up by the NHPL are insufficient on their own, since 
the associated legal provisions are too broad and not well defined. Phrasing such as 'a nation-wide overall inventory to be conducted and regularly updated' and 'It must encompass all properties that form the entire entity of the national heritage' (Article III) (P. 7) can be interpreted in different ways since the terms 'all properties' and 'entire entity' are so general as to include virtually any cultural entity. This generalisation is too subjective if we are to establish systematic records for the various classes of the archaeological resource. Establishing specific and detailed recording guidelines should be considered an essential first step.

\section{- Absence of an organisation collectively assigned to record the archaeological resource} To date there is no specific body, or part thereof, assigned to handle responsibility for recording the national resource. Thus, there is no clear plan to establish and maintain a comprehensive record that makes information available to planning authorities and fulfils the demands of conservation, research and community education.

\section{- Centralisation in managing the archaeological resource}

The MHC is centrally located in the capital and has no local administrative branches, except for the General Directorate of Heritage in Salalah. This has led to much effort being wasted that could have gone into recording known and newly-discovered sites. Likewise, the absence of interested private and voluntary organisations has led to a loss of potential effort and information sources that could expand the archaeological record.

- The level of funding and the adequacy of record maintenance facilities

Currently, there is no specific percentage of the MHC's annual budget allocated to the creation and development of archaeological records. This seriously retards the move towards establishing systematic and well-planned record keeping.
It also increases the MHC's deficit in terms of needed administrative and technical facilities.

\section{- Staff qualifications and training in the field of recording}

There is an obvious dearth of qualified personnel in the Ministry of Heritage and Culture. The current staff is insufficient, in terms of number and qualifications, even for performing the department's basic duties, especially when one remembers the total area of the country, the difficulties of its topography, and the diversity of its archaeological resource. In addition, there are no formal training programmes available for those few staff members recording in the field.

\section{- Level of cooperation and coordination among organisations}

In addition to the $\mathrm{MHC}$, which is the main arm of government responsible, a number of other bodies have been asked to assist in implementing the NHPL through their participation in 'a Ministerial Committee to be formed of the Ministers of Interior, Social Affairs and Labour, Land Affairs and Municipalities and the Under-secretary of Financial Affairs before making any final decisions in line with the provisions of the appended Law in so far as the matters of corporate importance are concerned' (Article IV of the Royal Decree 6/80, p. 3). Moreover, all other government ministries and authorities are requested 'to do whatever is needful for implementing this Law, each within its area of jurisdiction' (Article IV of the Royal Decree 6/80, p. 4). Despite this obligation, current cooperation between the Ministry of Heritage and Culture and other government bodies is minimal with regard to recording the archaeological resource. The only exception is a joint project between the $\mathrm{MHC}$ and the National Surveys Authority (NSA) of the Ministry of Defence, which in 2005 produced a map of Omani Archaeological sites (Biubwa AlSabri, personal comm., 2007). The map is owned by the MHC and was given the following name: Sultanate of Oman: The Major Archaeological Sites. It was produced on a scale of $1: 1,300,000$ 
and included 158 sites considered by the MHC to be major. They were plotted and recorded according to their geographical coordinates. Two versions of the map were produced: one showed sites on a topographic map and the other sites on a Landsat satellite image. It was published in two forms - a hard and a soft copy. The former can be accessed by all users, while the latter is of limited access. It is anticipated that this map will be updated every five years.

\section{CONCLUSIONS AND RECOMMENDATIONS}

This paper has shown that the use of electronic databases for recording Oman's archaeological resource is still at an embryonic stage. Government awareness of the importance of recording the resource dates back to 1980 with the enactment of the NHPL, which obliges the $\mathrm{MHC}$ to establish and update a national inventory of all the country's heritage properties. Since then, considerable amounts of time, money and effort have been devoted by the $\mathrm{MHC}$ to recording the various contents of the resource. Two databases constructed in 1998 represent the earliest and only achievements of the MHC in recording the resource electronically. However, they have their own limitations and thus play a very limited role in terms of resource research and management. In addition, current recording quality is affected by a number of problems that can be summarised as follows: ambiguity, generalisation, and insufficiency of legislative measures relating to the recording process; domination by traditional recording practices adopted by the $\mathrm{MHC}$ since its establishment; absence of an organisation specifically assigned to recording the resource and over-centralization in managing it. Quality is also affected by insufficient funding, the inadequacy of record maintenance facilities, the paucity of staff qualifications and training, and minimal cooperation and coordination between relevant bodies. All these factors explain the current inability to study comprehensively and systematically the nature, characteristics, distribution patterns and conditions of resource components.

Based on these findings and the above discussion, the following comments and recommendations are offered:

- There is an urgent need for a comprehensive strategy to record the various components of Oman's archaeological resource. This can be achieved by enhancing current databases and/or by creating new databases with up-todate recording techniques that can integrate existing records.

- The NHPL requirement for the MHC to construct a single inventory for the whole 'national heritage' is conceptually and practically very subjective. There is a need for specialised inventories for all categories of the nation's cultural property. These inventories would provide information about the real content, size and diversity of all categories of the national heritage in more professional, systematic and consistent ways and would, in turn, help in the shaping of successful future management plans.

- The legal provisions relating to the country's archaeological resource should be revised and accompanied by specifications and guidelines about the ways in which the recording process can be pursued. The revision of Oman NHPL must be seen as part of an overall management strategy. This would, of course, also include provisions for survey, salvage, protection, and public material culture presentations.

- There is a need to establish a body specifically assigned to recording the nation's archaeological resource.

- There is a need for a comprehensive survey strategy that would cover all Oman's archaeologically important regions. This 
would produce an archaeological map of the country, and hence would prepare the ground for resource recording in a systematic way, using modern information technology.

- Establishing local branches of the MHC would certainly facilitate and expand the recording process.

- Funding for archaeological recording should be increased and this should not only be the responsibility of the MHC. Other related bodies and organisations should also participate.

- There is a need to establish qualification and training programmes for staff in the field of recording.

- Recording the archaeological resource should not be looked on as an easy task. It takes great effort and support from archaeologists, record creators, curators and the public.

- Coordination and cooperation between the Ministry of Heritage and Culture and other governmental organisations around issues of recording the archaeological resource are vital. Well-defined responsibilities and comprehensiveguidelinesarerecommended in this respect.

- When constructed, new archaeological records should include the following: conservation and management information concerning survival, condition, hazards, land-use, accessibility, site significance and restoration.

- There is a need to improve the existing archaeological databases or to integrate them into a new record.

- When constructed, the new record should be considered as a central body of information regarding the types and nature of the different components of the historical environment. It should be constantly improved so that it can be used for purposes of research, planning, education and the economy. It should also be seen as an index of the various types of archaeological activities that have been undertaken over the years, thus showing what monuments and periods have received attention. This would help when deciding management and research priorities. It should also be used to maintain, curate and index an archaeological archive of the different types of material (e.g. bibliographies, plans, photographs) resulting from archaeological activity. Additionally, it should also be used to provide national planning authorities with information and advice on matters relating to the utilisation of the historical environment and to help them in monitoring and controlling the implications of their policies.

- It is important that the new record should be used to develop an information service policy in order to regulate access to this and other services. It should also establish different forms of supervised and unsupervised access channels to ease and control record and collection accessibility. Making this record available online would enable remote users to search the database.

- Using appropriate data standards and guidelines for physical structures, the new record should include all contents relevant for the construction of future archaeological databases.

- The new record must also have a clear information collection policy. This would help to identify the sources of information currently available and unavailable. It would also help to identify and quantify financial support necessary for updating purposes. As the number of sources is continuously increasing, this policy should be constantly revised and updated. There is, further, a need to establish 
a library attached to the record, which would include all sources of information relating to the recording of the national resource. The existing library of the Department of Excavation and Archaeological Studies at the MHC could be used as a nucleus for a larger and welldeveloped facility.

- The MHC should oblige all individuals and organisations undertaking any new projects related to the historical environment to provide the new record with detailed information about their activities.

- The record should also develop data standards regarding its structure and contents. This would ensure consistency in recording the archaeological resource and help record curators to check data's technical and academic validity and reliability. It would also facilitate the future harmonisation and integration of the record with other records.

- Recording tools and new record applications should be continuously enhanced to meet functional requirements and be compatible with the structure and standards of other databases. Training and technical support should be provided as an integral part of any plan to replace recording tools and applications.

- In addition to core curators needed to handle key functions of the database, there is also a need for local inspectors to be appointed in each of Oman's eight administrative governorates and regions in order to update the record regularly with new information about sites and monuments that lie within their areas.

- It is important to consult the organisations and bodies expecting to use this record about matters of expanding its extent. This would also give them an opportunity to discuss their needs. This relationship would create a firm strategy for increasing the financial and human resources necessary for supporting the development of the new record.

\section{ACKNOWLEDGMENTS}

I would like to express my deep appreciation to the following colleagues for their invaluable help: Professor John Hunter and Dr. Roger White (University of Birmingham, UK); Professor Ali EIMahi and Professor Adrian Roscoe (Sultan Qaboos University, Oman); Mr. Kelig-Yann Cotto and Mr. Martin Menu (France); Mr. Sultan Al-Bakri (Ministry of Heritage and Culture, Oman). 


\section{REFERENCES}

- Arroyo-Bishop, D. \& Zarzosa, M. T. L. 1992. The ArcheoDATA System: A Method for Structuring a European Archaeological Information System (AIS), In Larsen, C. (Ed.), Sites \& Monuments: National Archaeological Records. The National Museum of Denmark, DKC, pp. 133-154.

- Barcelo, J. A.; Briz, I. and Vila, A. 1999. New Techniques for Old Times, CAA 98. Computer Applications and Quantitative Methods in Archaeology. Proceedings of the 26th Conference, Barcelona, March 1998. BAR International Series 757, Oxford.

- Barcelo, J. A.; Briz, I. and Vila, A. 1999. New Techniques for Old Times. A General Introduction to Computing Archaeology. In Barcelo, J. A.; Briz, I. and Vila, A. (eds), New Techniques for Old Times, CAA 98. Computer Applications and Quantitative Methods in Archaeology. Proceedings of the 26th Conference, Barcelona, March 1998. BAR International Series 757, Oxford, pp. 1-15.

- Greene, K. 1983. Archaeology: An Introduction. London: Routledge.

- Larsen, C. (Ed.) 1992. Sites \& Monuments: National Archaeological Records. The National Museum of Denmark, DKC.

- Larsen, C. 1992. Preface. In Larsen, C. (Eds.) Sites and Monuments: National Archaeological Records. The National Museum of Denmark, DKC, pp. 3-4.

- Madsen, T. 2001. Transforming Diversity into Uniformity-Experiments with Meta-Structures for Database Recording. in Stancic, Z. \& Veljanovski, T. (Eds.), Computing Archaeology for Understanding the Past, CAA2000. Computer Applications and Quantitative Methods in Archaeology. Proceedings of the 28th Conference, Ljubljana, April 2000. BAR International Series 931, Oxford, pp. 101-5.

- Niccolucci, F., D’Andrea, A. \& Crescioli, M. 2001. Archaeological Applications of Fuzzy Databases. in Stancic, Z. \& Veljanovski, T. (Eds.), Computing Archaeology for Understanding the Past, CAA2000. Computer Applications and Quantitative Methods in Archaeology. Proceedings of the 28th Conference, Ljubljana, April 2000. BAR International Series 931, Oxford, pp. 107-115.

- Reilly, P. \& Rahtz, S. 1992. How does Modern Information Technology Meet the Demands of Archaeology? in Reilly, P. \& Rahtz, S. (Eds.), Archaeology and the Information Age: A Global Perspective. London: Routledge, on the back cover.

- Royal Decree 6/1980 1980. The Omani National Heritage Protection Law (in Arabic), Official Gazette. Muscat.

- Schloen, D. 1999. Database Design and the Electronic Publication of Archaeological Information. in Barcelo, J. A.; Briz, I. \& Vila, A. (Eds.), New Techniques for Old Times, CAA 98. Computer Applications and Quantitative Methods in Archaeology. Proceedings of the 26th Conference, Barcelona, March 1998. BAR International Series 757, Oxford, pp. 299-302. 
- Stancic, Z. \& Veljanovski, T. 2001. Computing Archaeology for Understanding the Past, CAA2000. Computer Applications and Quantitative Methods in Archaeology. Proceedings of the 28th Conference, Ljubljana, April 2000. BAR International Series 931, Oxford.

- Thomas, D. H. 1978. The Awful Truth about Statistics in Archaeology. American Antiquity, 34(2), pp. 231-244.

- Wheatley, D. 1995. The Impact of Information Technology on the Practice of Archaeological Management. in Cooper, M. A., Firth, A., Carman, J. \& Wheatley, D. (Eds.), Managing Archaeology. London \& New York: Routledge, pp. 163-174. 